\title{
Kinetic and Thermodynamics studies for Castor Oil Extraction Using Subcritical Water Technology
}

\author{
Wael Abdelmoez ${ }^{1 *}$, Eman Ashour ${ }^{1}$, Shahenaz M. Naguib ${ }^{1}$, Amr Hilal $^{2}$, \\ Dalia A. Al Mahdy ${ }^{3}$, Engy A. Mahrous ${ }^{3}$ and Essam Abdel-Sattar ${ }^{3}$ \\ ${ }^{1}$ Department of Chemical Engineering, El-Minia University, 61519 El-Minia, EGYPT \\ ${ }^{2}$ IT \& M Marketing, Cairo, EGYPT \\ ${ }^{3}$ Pharmacognosy Department, Faculty of Pharmacy, Cairo University, 11562 Cairo, EGYPT
}

\begin{abstract}
In this work both kinetic and thermodynamics of castor oil extraction from its seeds using subcritical water technique were studied. It was found that the extraction process followed two consecutive steps. In these steps, the oil was firstly extracted from inside the powder by diffusion mechanism. Then the extracted oil, due to extending the extraction time under high temperature and pressure, was subjected to a decomposition reaction following first order mechanism. The experimental data correlated well with the irreversible consecutive unimolecular-type first order mechanism. The values of both oil extraction rate constants and decomposition rate constants were calculated through non-linear fitting using DataFit software. The extraction rate constants were found to be $0.0019,0.024,0.098,0.1$ and $0.117 \mathrm{~min}^{-1}$, while the decomposition rate constants were $0.057,0.059,0.014,0.019$ and $0.17 \mathrm{~min}^{-1}$ at extraction temperatures of $240,250,260,270$ and $280^{\circ} \mathrm{C}$, respectively. The thermodynamic properties of the oil extraction process were investigated using Arrhenius equation. The values of the activation energy, Ea, and the frequency factor, $\mathrm{A}$, were $73 \mathrm{~kJ} \mathrm{~mol}^{-1}$ and 946, $002 \mathrm{~min}^{-1}$, respectively. The physicochemical properties of the extracted castor oil including the specific gravity, viscosity, acid value, $\mathrm{pH}$ value and calorific value were found to be 0.947 , $7.487,1.094 \mathrm{mg} \mathrm{KOH} / \mathrm{g}, 6.1$, and $41.5 \mathrm{MJ} / \mathrm{Kg}$, respectively. Gas chromatography analysis showed that ricinoleic acid $(83.6 \%)$ appears as the predominant fatty acid in the extracted oil followed by oleic acid (5.5\%) and linoleic acid $(2.3 \%)$.
\end{abstract}

Key words: castor seed, ricinoleic acid, subcritical water extraction, kinetic and thermodynamic study

\section{Introduction}

The past decade had witnessed an intense interest in the use of subcritical water technology (SWT) in separation processes. SWT was an alternative extraction method whereby water, instead of organic solvents is used as the extraction media. On heating within the critical point of water (temperature $<374^{\circ} \mathrm{C}$, pressure $<22.1 \mathrm{MPa}$ ) under enough pressure to maintain the liquid state, water (subcritical water in this state) was reported to have distinctive properties. These were; a low dielectric constant and a high ion product. Many extractable components from different biomasses could easily be extracted under these conditions $^{1,2)}$.

The subcritical water extraction (SWE) process could be proposed to have six sequential steps: (1) rapid fluid entry; (2) desorption of solutes from matrix active sites; (3) diffusion of solutes through organic materials; (4) diffusion of solutes through static fluid in porous materials; (5) diffusion of solutes through layer of stagnant fluid outside particles; and (6) elution of solutes by the flowing bulk of fluid.

Based on research works published in recent years, SWE has proven to be a cleaner, faster and cheaper technique than the conventional extraction methods.

Relatively large amounts of oils, organic acids, and amino acids were reported to be extracted from oil containing biomasses such as fish, squid entrails and meat wastes by $\mathrm{SWT}^{3)}$. Moreover, essential or fixed oils were extracted from either a whole plant or plant seeds using SWT. As particular examples, coriander oil was extracted from their fruits $^{4}$, as well as, both cottonseed and jojoba oils using $\mathrm{SWT}^{5,6)}$. Ravber et al. ${ }^{7)}$ also, proposed SWE as an alternative and greener processing method for simultaneous removal of oil and water soluble phase from sunflower seeds where the produced oil had much higher antioxidant

\footnotetext{
*Correspondence to: Wael Abdelmoez, Department of Chemical Engineering, El-Minia University, 61519 El-Minia, EGYPT

E-mail: drengwael2003@yahoo.com

Accepted February 22, 2016 (received for review December 27, 2015)

Journal of Oleo Science ISSN 1345-8957 print / ISSN 1347-3352 online

http://www.jstage.jst.go.jp/browse/jos/ http://mc.manusriptcentral.com/jjocs
} 
capacities than that extracted using the Soxhlet method. Furthermore, biomass conversion was successfully carried out using SWT, where wheat straw was converted into sugars in a very short time under subcritical water conditions ${ }^{8)}$.

SWE has been used in a wide array of applications in the extraction of the active compounds from herbs, such as rosemary, German chamomile, senna, valerian, Baikal skullcap, Wuweizu, ginger, Astragalus etc. ${ }^{9}$. Those extracts were demonstrated to exhibit a composition essentially similar to that of the corresponding methanol or aqueous alcohol extracts. Liang and $\mathrm{Fan}^{10)}$ published a review on application of SWE in pharmaceutical industry. The authors reported the application of SWE on preparation of essential oils of different kinds of herbs, including fennel, thyme, marjoram, peppermint, laurel, eucalyptus, and clove buds, etc., which were compared with hydrodistillation, supercritical carbon dioxide and extraction methods. SWE has been proved good to extract plant phenolic compounds including tannins, flavonoids, anthraquinones, lignin and some simple phenols. Kubatova et $a l^{11)}$ compared the extraction of kava lactones, active ingredients from the roots and rhizomes of Piper methysticum, using SWE with that of soxhlet extraction, ultrasonic extraction in boiling water and acetone extraction, where the extraction rate of the SWE was much higher than other methods, whether the pepper was crushed or not. Phenolic compounds were also extracted from grape pomace using SWE with higher polyphenols, flavonoids and antioxidant activity compared to conventional organic solvent extraction ${ }^{12}$. Similar results were obtained for phenolics and flavonoids from Coriandrum seeds obtained with SWE showing higher content when compared with conventional solid-liquid extraction and even modern extraction techniques, such as ultrasound- and microwave-assisted extraction $^{13)}$. In addition, Baek et al. ${ }^{14)}$ examined the influence of different temperatures and time on the SWE yield of antioxidant nutrients from licorice and found that the SWE significantly affected the antioxidant activities and nutraceutical compound levels of the extracts.

Castor plant (Ricinus communis L., family Euphorbiacae) is a tree or shrub that could grow above $10 \mathrm{~m}$ high, reaching an age of four years. Castor seeds contain about $46-55 \%$ oil by weight ${ }^{15)}$. Castor grows in the humid tropics to the sub-tropical dry zones (optimal precipitation $750-1000 \mathrm{~mm}$, temperature $15-38^{\circ} \mathrm{C}$ ). The oil of castor plant is viscous, pale yellow, non-volatile with a bland taste, a slight odor and used as a purgative. Relative to other vegetable oils castor oil has a good shelf life and it does not turn rancid unless subjected to excessive heat. The oil is characterized by high viscosity although this is unusual for a natural vegetable oil. This behavior is largely due to hydrogen bonding of its hydroxyl groups. It is soluble in alcohols in any proportion but it has only limited solubility in aliphatic petroleum solvents ${ }^{15)}$. It has different applications in adhesives, coatings, soaps, lubricants, paints and dyes ${ }^{16)}$. Recently, Sanchez et al. demonstrated the use of subcritical methanol for transesterification of castor oil for biodiesel production ${ }^{17)}$.

There are many extraction methods for obtaining the oil from the castor seeds. The extraction of oil from the castor seeds could be carried out in one step or combination of multi steps, such as mechanical pressing and solvent extraction ${ }^{18)}$. The examples of the mechanical pressing were hydrate presses and continuous screw presses. However, the most effective way to obtain the oil from the seed was hot pressing using a hydraulic press followed by solvent extraction. In the mechanical pressing, the seeds were crushed to remove them from the shell and bring the raw material to low moisture content by heating in a steamjacketed vessel. Then, the crushed seeds were subjected to hydraulic presses for oil extraction ${ }^{19)}$. Such remaining oil could be recovered only by solvent extraction. The extraction process could be carried out using solvents such as heptane, hexane and petroleum ether ${ }^{15)}$.

In the present work, the extraction of fixed oil from castor seeds (Ricinus communis L.) using SWT was carried out to demonstrate both the optimum oil extraction conditions as well as the kinetic and thermodynamics studies needed for the engineering design of the pilot production of castor oil. Characterization of the extracted castor oil was also conducted and presented.

\section{Experimental}

\subsection{Materials}

\subsubsection{Plant material}

The castor seeds (Balady cultivar) used in this study (for both conventional extraction and SWT) were obtained from El-Minia market, Egypt. Fresh seeds were stored in polyethylene bags at room temperature. Samples were subjected to de-hulling and cleaning, then used for the extraction process.

\subsubsection{Reagents and Chemicals}

All chemicals and materials used in this work were locally manufactured in Egypt. Methanol used for measuring the extracted oil in the seed was obtained from El-Nasr Chemical (Cairo, Egypt). Distilled water, prepared at ElMinia University in Egypt, was used as the extracting solvent in subcritical water extraction. Authentic reference samples for gas chromatography (GC) analysis of the fatty acid methyl esters (FAME) were obtained from Nu-check Prep, Minnesota, USA.

\subsection{Methods}

2.2.1 Determination of the oil content of castor seeds

The oil content of the castor seeds was determined 
before starting the subcritical water experiments. Dried castor seeds used in this study were first de-hulled and grinded. Five grams of grinded de-hulled seeds were extracted with $200 \mathrm{~mL}$ of methanol ${ }^{20)}$. The content was mixed, and heated using a magnetic stirrer hot plate. The extraction was carried out at $60^{\circ} \mathrm{C}$ for 12 hours. The seeds were then separated from the extraction mixture by filtration and the extracted oil was recovered by evaporating the solvent. Measurements were done in triplicate to reduce the error.

\subsubsection{Subcritical water extraction}

\subsubsection{Subcritical water extraction of castor seeds}

The subcritical water extraction was carried out in stainless steel pipes SUS 316, inner dimensions $1.68 \mathrm{~cm} \times 15 \mathrm{~cm}$ (with a reactor volume of $34 \mathrm{~cm}^{3}$ ) and Swadgelock caps. De-hulled grinded castor seeds were charged into the reactor tube, and distilled water was added as an extraction solvent. The reactor was sealed and immersed in an oil heating bath (Thomas Kagaku Co. Ltd.). It was important to note here as a safety comment that the sealed tube should not be overfilled to prevent hydraulic pressure of the expanding liquid from fracturing the tube vessel ${ }^{8)}$.

The extraction was carried out at $270^{\circ} \mathrm{C}$ for $30 \mathrm{~min}$., and the pressure inside the reactor was estimated from the steam table for the subcritical conditions (saturated steam). After the desired reaction time is achieved, the reactor was immediately cooled down by immersing it into a cold-water bath.

The extraction product was separated into three phases: the oil phase, the aqueous phase (including oil and water), and the solid phase. The three phases were separated through simple centrifugation and vacuum filtration processes. First of all, the phases were clearly separated using centrifugation just after delivering the reactor content. Most of the extracted oil by subcritical water was separated in this centrifugal step as a clear upper layer and it was collected using a pipette. However, traces of the oil were still emulsified in the aqueous phase, as well as, entrapped within the solid phase. These remaining traces were obtained by extraction with hexane to accurately calculate the overall yield. The hexane was then evaporated by heating in an oven at $60^{\circ} \mathrm{C}$. Finally, the extracted oil was weighed and the data was recorded.

2.2.2.2 Optimization of subcritical water oil extraction

The optimization step of the castor seed oil extraction using SWT included exploring the effect of the different variables affecting the extraction process. These variables were as follows:

i. Extraction temperature. ii. Extraction time. iii. Feed to solvent (water) ratio.

Determination of the optimum extraction temperature

To determine the optimum extraction temperature, the same procedure described in section 2.2.2.1 was followed, changing only the extraction temperature and keeping other parameters, the temperatures tested were 240,250 , 260,270 , and $280^{\circ} \mathrm{C}$.

Determination of the optimum extraction time

For the optimum extraction time determination, once more the same procedure described in section 2.2.2.1 was followed, changing only the extraction time. The extraction was done at $270^{\circ} \mathrm{C}$ (which, as will be discussed later, was found to be the optimum extraction temperature) and feed to solvent ratio of 1:2. The tested extraction times were in the range of $10-50$ min while keeping other parameters constant.

Determination of the optimum feed to solvent (water) ratio

The optimum feed to solvent (water) ratio was determined as in section 2.2.2.1, changing only the amount of water added to the reactor. For $10 \mathrm{~g}$ of the grinded seeds, the amount of water used was 10,20,30, 40 and $50 \mathrm{~mL}$, which represent feed to solvent ratio of 1:1,1:2, 1:3, 1:4 and 1:5, respectively. The extraction was done at $270^{\circ} \mathrm{C}$ for 30 min (which, as will be discussed later, were found to be the optimum extraction temperature and time, respectively).

2.2.2.3 Characterization of extracted castor oil by SWT

Determination of the acid value

The oil sample ( $5 \mathrm{~g})$ was dissolved in ethanol. Phenolphthalein indicator was used to determine the $\mathrm{pH}$ change during the esterification reaction ${ }^{5)}$. The titration was carried out against an aqueous solution of $0.1 \mathrm{~N} \mathrm{KOH}$. Acid value (A.V.) was determined in mg according to the equation given below:

$$
\text { Acid Value }=\frac{56.1 * \mathrm{~N} * \mathrm{~V}}{\mathrm{M}}
$$

where: $\mathrm{N}$ : normality of $\mathrm{KOH}$ solution

$\mathrm{V}$ : the volume of solution employed for titration, $\mathrm{mL}$

$\mathrm{M}$ : weight of fatty acids sample, $\mathrm{g}$

Determination of the specific gravity

Density bottle was used to determine the density of the oil. A clean and dry $25 \mathrm{~mL}$ specific gravity bottle was weighed $\left(\mathrm{W}_{0}\right)$, filled with the oil then reweighed to give $\left(\mathrm{W}_{1}\right)$. The oil was substituted with water and weighed to give $\left(\mathrm{W}_{2}\right)$. Specific gravity (Sp.gr) was expressed as:

Sp.gr $=\left(\mathrm{W}_{1}-\mathrm{W}_{0}\right) /\left(\mathrm{W}_{2}-\mathrm{W}_{0}\right)$

Mass of the substance / Mass of an equal volume of water

\section{Determination of the viscosity}

The oil sample $(50 \mathrm{~mL})$ was poured into a clean dry beaker and was introduced to a viscosity device(DV-III Ultra Rheometer, BROOKFIELD, U.S.A). In a few seconds, the value of viscosity was recorded.

Determination of the $\mathrm{pH}$ value

Two grams of castor oil was poured into a clean dry 25 $\mathrm{mL}$ beaker, $13 \mathrm{~mL}$ of hot distilled water was added to the sample and stirred slowly. It was then cooled in a cold water bath to $25^{\circ} \mathrm{C}$. The $\mathrm{pH}$ meter (pp-206 pH/mV/Temp Meter, EZODO, TAIWAN) was standardized with buffer so- 
lution, the electrode was immersed into the sample and the $\mathrm{pH}$ value was read and recorded.

Determination of the calorific value

Calorific value or heat of combustion was determined at $25^{\circ} \mathrm{C}$ (the initial temperature of the fuel and the oxygen) and the final temperature of the products of combustion. Heat of combustion was determined by burning a weighed sample in an oxygen bomb calorimeter (Parr 6200, Illinois) under controlled conditions. The result was collected through the device interface in a digital form.

Analysis of the fatty acid profile

The composition of the fatty acids was determined as fatty acids methyl esters (FAME) for both oil samples prepared by conventional solvent extraction (section 2.2.1) and subcritical water extraction methods. Both oil samples were subjected to saponification, followed by methylation of the obtained free fatty acids to prepare the FAME ${ }^{21)}$. GLC analysis of the FAME was carried out on an Agilent GC system equipped with a flame ionization detector (FID) and a 5\% phenyl methyl polysiloxane capillary column (DB-5, $30 \mathrm{~m} \times 0.25 \mathrm{~mm}$ I.D. $\times 0.25 \mu \mathrm{m}$ film). The injector temperature was $200^{\circ} \mathrm{C}$, detector at $220^{\circ} \mathrm{C}$ and the GC oven was kept at $140^{\circ} \mathrm{C}$ and heated by the rate of $5^{\circ} \mathrm{C} / \mathrm{min}$ up to $200^{\circ} \mathrm{C}$. The carrier gas was nitrogen $(30 \mathrm{~mL} / \mathrm{min})$. The analysis was carried out by injecting $2 \mu \mathrm{l}$ of the sample solution into the GC. Fatty acid methyl esters were identified by comparing their retention time with those of the available reference standards. The amount of each component was calculated via peak area measurement using a computing integrator.

\section{Theoretical part}

\subsection{Kinetics studies}

The oil extraction process could be viewed as an irreversible consecutive unimolecular-type first order. In which, the oil was first extracted from inside the seed by diffusion following a first order-like mechanism. Then the extracted oil, due to extending the extraction time under the high temperature and pressure, was subjected to a decomposition reaction following a first order mechanism. Accordingly, the oil extraction process could be simplified into the following reaction scheme,

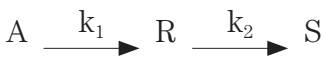

Where, A, R and S, represent the total castor oil in the seed, extracted castor oil, and the decomposition product, respectively and $k_{1}$ and $k_{2}$ represent the specific reaction rate constants for the extraction and decomposition steps, respectively. The rate Equations for the three components were:

$$
\begin{aligned}
& \mathrm{dC}_{\mathrm{a}} / \mathrm{dt}=-\mathrm{k}_{1} \mathrm{C}_{\mathrm{a}} \\
& \mathrm{dC}_{\mathrm{r}} / \mathrm{dt}=\mathrm{k}_{1} \mathrm{C}_{\mathrm{a}}-\mathrm{k}_{2} \mathrm{C}_{\mathrm{r}} \\
& \mathrm{dC}_{\mathrm{s}} / \mathrm{dt}=\mathrm{k}_{2} \mathrm{C}_{\mathrm{r}}
\end{aligned}
$$

Where $C_{a}, C_{r}$ and $C_{s}$, represent the concentration of the total castor oil in the seed, the concentration of extracted castor oil, and the concentration of decomposition product, respectively.

By integrating and rearrangement, the final variation in concentration of the extracted castor oil, $\mathrm{R}$, was:

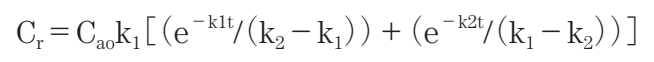

Where $\mathrm{C}_{\mathrm{ao}}$ represents the initial concentration of the castor oil in the seeds. Equation (4) had been used to elucidate the concentration time course of castor oil extraction.

\subsection{Thermodynamic study}

The oil extraction process was also analyzed thermodynamically. Arrhenius equation was used for describing the temperature dependence of the reaction rate using equation (5).

$$
\mathrm{K}=\mathrm{A} \exp [-\mathrm{Ea} / \mathrm{RT}]
$$

Where A was the pre-exponential factor (sometimes called frequency factor), Ea was the apparent activation energy, $\mathrm{T}$ was the absolute temperature, and $\mathrm{R}$ was the gas constant $\left(8.31451 \mathrm{~J} .(\mathrm{mol.} \mathrm{K})^{-1}\right)$.

By plotting $\mathrm{ln} \mathrm{k}$ vs. 1/T, a linear relationship was obtained and one can determine $\mathrm{Ea}$ from the slope $(-\mathrm{Ea} / \mathrm{R})$ and $\mathrm{A}$ from the y-intercept.

\section{Results and discussion}

\subsection{Determination of oil content in the castor seeds}

The first step was to estimate the amount of oil contained in the castor seed used in this study. The oil content of the given sample was measured using methanol as a solvent, it was found that the oil content represented $53 \%$ on dry weight basis of the de-hulled grinded seeds.

The percentage of oil extraction using subcritical water was based on this oil content measured above.

\subsection{Subcritical water extraction}

To find out the optimum extraction conditions, the extraction process was carried out under different conditions. At a time, only one parameter was changing while the other parameters were kept constant. The tested extraction parameters were the temperature, time of extraction and the feed to solvent (water) ratio.

4.2.1 Effect of temperature on the extraction yield

To study the effect of temperature on the extraction 
(a)

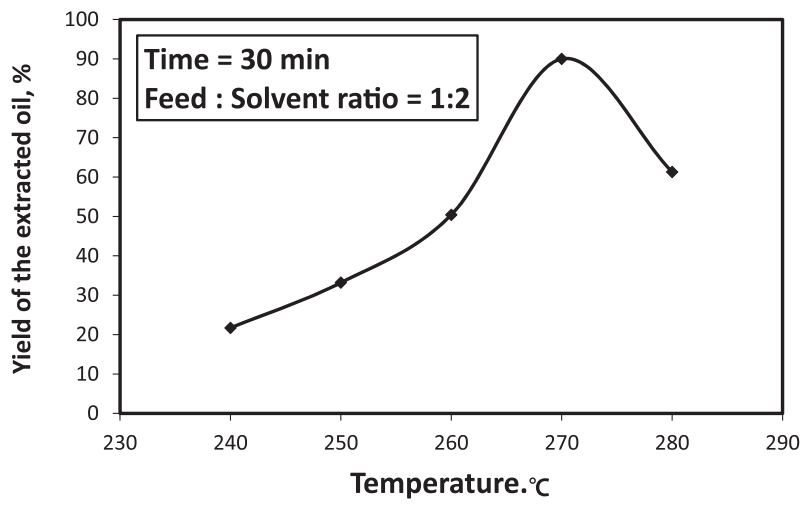

(b)

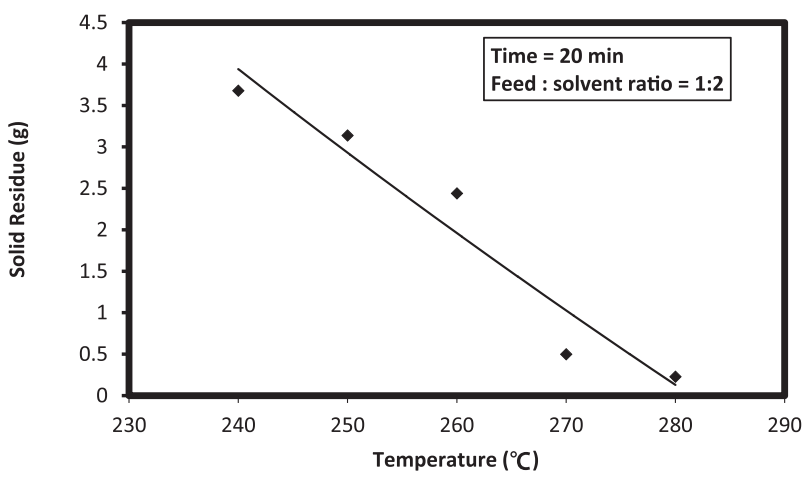

Fig. 1 Effect of the extraction temperature on: (a) the yield of the extracted oil, (b) the extraction product solid residues.

process, the sub-critical water extraction process was carried out by changing the extraction temperature while keeping other parameters constant. The tested extraction temperatures were in the range of $240-280^{\circ} \mathrm{C}$. The extraction proceeded for 30 minutes using $10 \mathrm{~g}$ of grinded seeds and $20 \mathrm{~g}$ of distilled water as a feed to solvent ratio of 1:2. Figure 1 shows the effect of the extraction temperature on the yield of the extracted oil and the total solid residue. The results indicated that the percentage of extracted oil increased with increase in the temperature to a certain level, and then it decreased (Fig. 1a). The maximum yield was $89.4 \%$ at $270^{\circ} \mathrm{C}$. The results also showed that the solid residue decreased with increasing in the extraction temperature (Fig. 1b).

4.2.2 Effect of extraction time on the extraction yield

The second studied parameter was the optimum extraction time. In this part of the study, the subcritical water extraction was carried out within a temperature range of 240 $-280^{\circ} \mathrm{C}$, and feed to solvent ratio $1: 2$. The extraction time was in the range of 10 to 50 minutes. Figure 2 shows the time course for castor oil extraction using subcritical water at different temperatures. The results showed that the absolute value of the maximum extracted oil percentage ob- tained increased with time and temperature up to a certain limit. However, it was observed that the percentage of the extracted oil increased up to a maximum value, then it was reduced by increasing the extraction time. Such reduction is due to the decomposition of some extracted oil into degradable products such as organic acids. These were either; dissolved in the liquid phase, which was indicated by changing the color of the liquid phase (became darker) or settled and separated from the floated oil phase. In addition, evolution of gases was observed during opening the reactor. According to the results, the optimum conditions of subcritical water extraction of castor seed oil would be as follows: extraction temperature $270^{\circ} \mathrm{C}$, time $30 \mathrm{~min}$.

4.2.3 Effect of feed to solvent ratio on the extraction yield

The optimum feed (grinded seeds) to solvent (water) ratio was determined by carrying out the extraction process at the obtained optimum temperature and extraction time of $270^{\circ} \mathrm{C}$ and $30 \mathrm{~min}$, respectively. The tested feed to solvent ratios were 1:1, 1:2, 1:3, 1:4, and 1:5. Figure 3 shows the effect of the feed to solvent ratio on the yield of extracted oil, where it was observed that increasing the amount of the solvent, relative to the amount of feed, increased the extracted oil percentage up to a maximum value then any increase in this ratio resulted in a dramatic reduction in the extracted oil percentage. This reduction may be explained in the light of the formation of water-oil emulsion. Since, some part of the extracted oil forms a very strong emulsion with water. The formed emulsion is not breakable under our experimental conditions and that part of emulsified oil could not be recovered in the extracted oil. The maximum extracted oil percentage was $96 \%$ at feed to solvent ratio of 1:2 and 1:3. In general, the feed to solvent ratio is responsible for the energy consumption of the process and the cost of post-extraction process (i.e. oil recovery from extracted effluent) accordingly; 1:2 will be considered the optimum feed to solvent ratio.

\subsection{Physicochemical properties of extracted castor oil}

Acid values are usually used as an indicator for edibility of oils ${ }^{22)}$. The acid value of the extracted castor oil was $1.094 \mathrm{mg} \mathrm{KOH} / \mathrm{g}$ of oil. The specific gravity of extracted castor oil from castor seeds was found to be 0.947 . This was in agreement with the standard reported in literature $^{16)}$. The value of the viscosity of the extracted castor oil was found to be $7.487 \mathrm{cP}$. The $\mathrm{pH}$ value of the extracted oil from castor seeds was measured and found to be 6.10 indicating that the extracted castor oil is more acidic. The calorific value of extracted castor oil was obtained to be 41.5 $\mathrm{MJ} / \mathrm{kg}$. Physical properties of the extracted castor oil is presented in Table 1.

\subsection{Fatty acids analysis of castor oil}

GC was used to identify the fatty acids present in the extracted castor oil. Figure 4 \& Table 2 show the GC chro- 


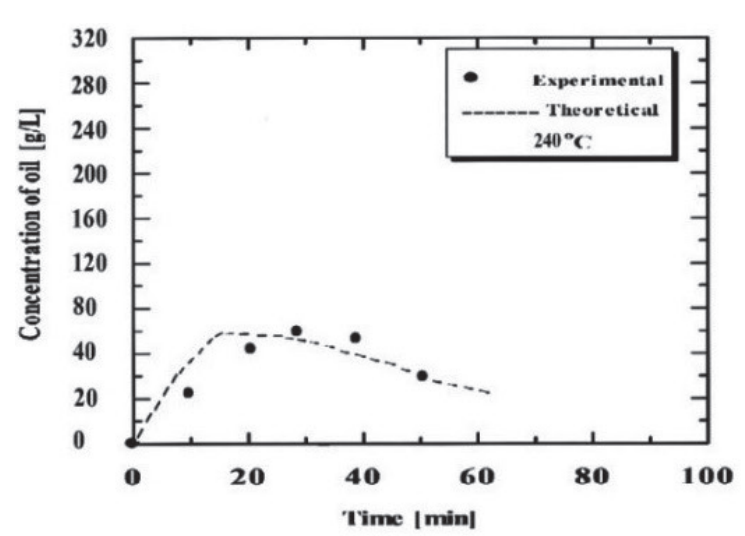

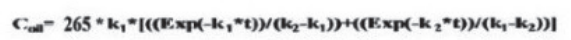
k1- 0.0993
$k 2-0.0978$
$|r|-0.865$

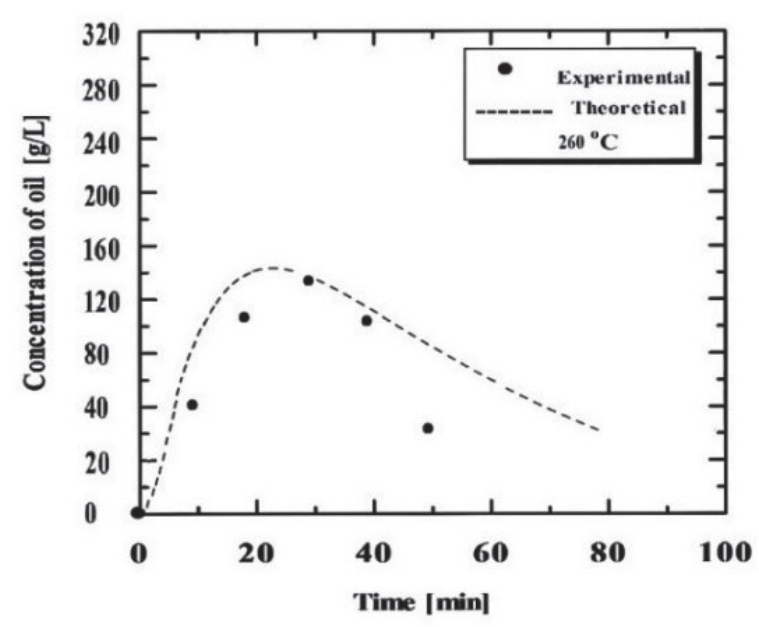

$C_{\text {edi }}=265 * k_{1} *\left|\left(\left(\operatorname{Exp}\left(-k_{1} * t\right)\right) /\left(k_{2}-k_{1}\right)\right)+\left(\left(\operatorname{Exp}\left(-k_{2} * t\right)\right) /\left(k_{1}-k_{2}\right)\right)\right|$

$\mathbf{k 1}=0.04$
$\mathbf{k} 2=0.0391$

|r| 0.891

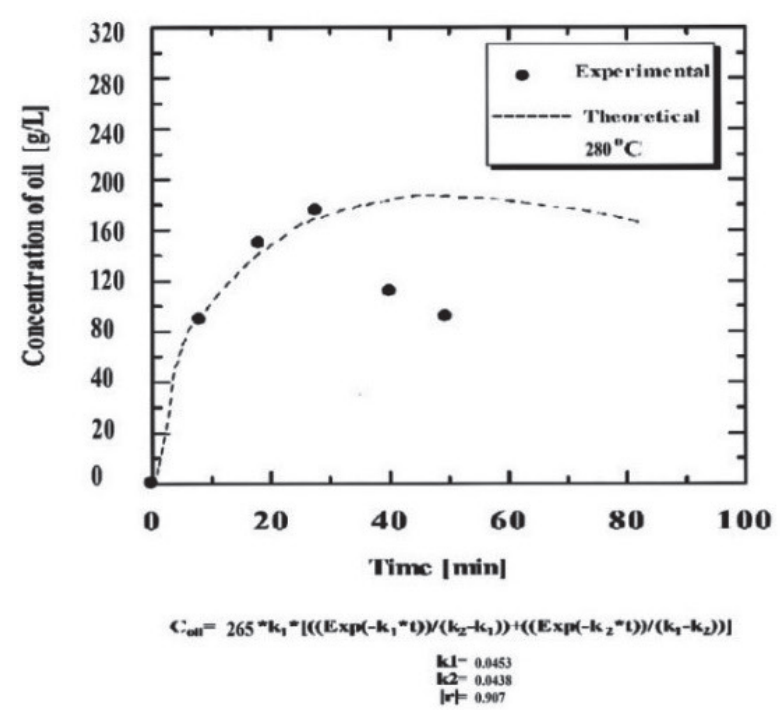

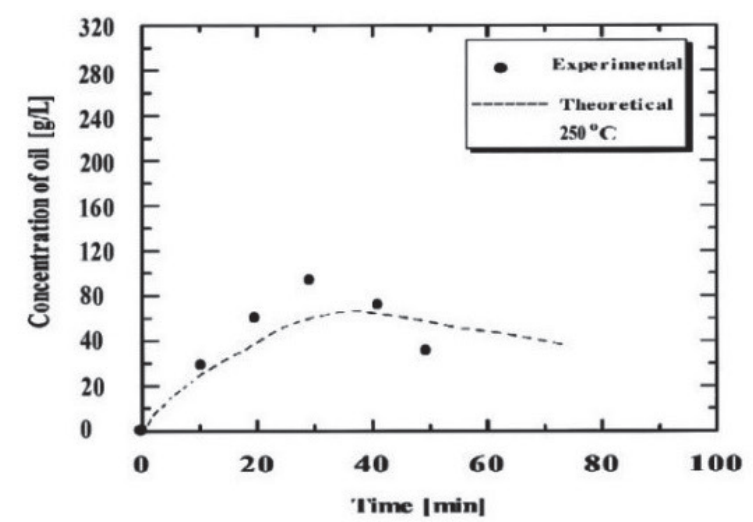

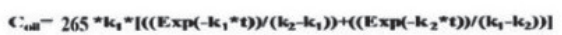
$k 1-0.0397$
$k 2=0.0385$
$k+1=0.88$

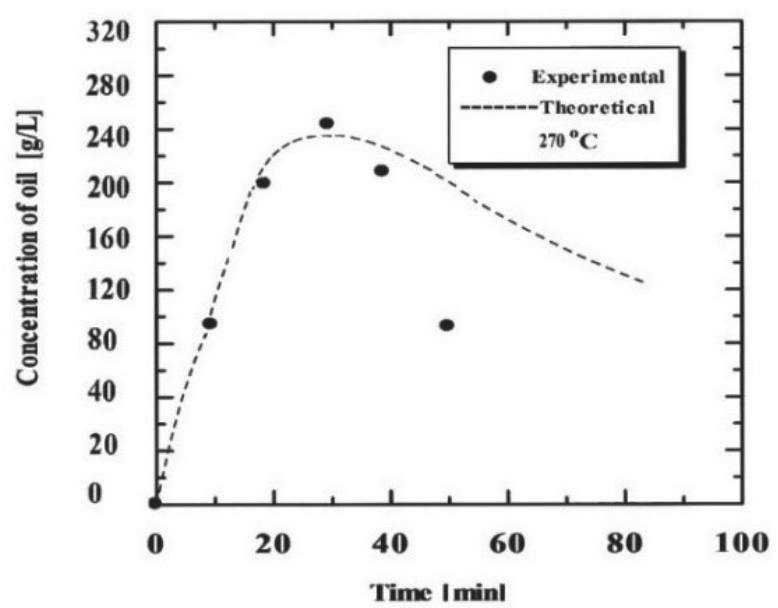

$\left.C_{\text {out }}=265{ }^{*} k_{1}{ }^{*} \mid\left(\left(\operatorname{Exp}\left(-k_{1}{ }^{*} t\right)\right) /\left(k_{2}-k_{1}\right)\right)+\left(\left(\operatorname{Exp}\left(-k_{2}{ }^{*} t\right)\right) /\left(k_{1}-k_{2}\right)\right)\right]$ $\mathbf{k 1}=0.0403$
$\mathbf{k 2}=0.0385$
$\mathrm{r}+0.912$

Fig. 2 The time course of the percentage of the extracted oil at different temperatures $\left(240,250,260,270\right.$ and $\left.280^{\circ} \mathrm{C}\right)$. 


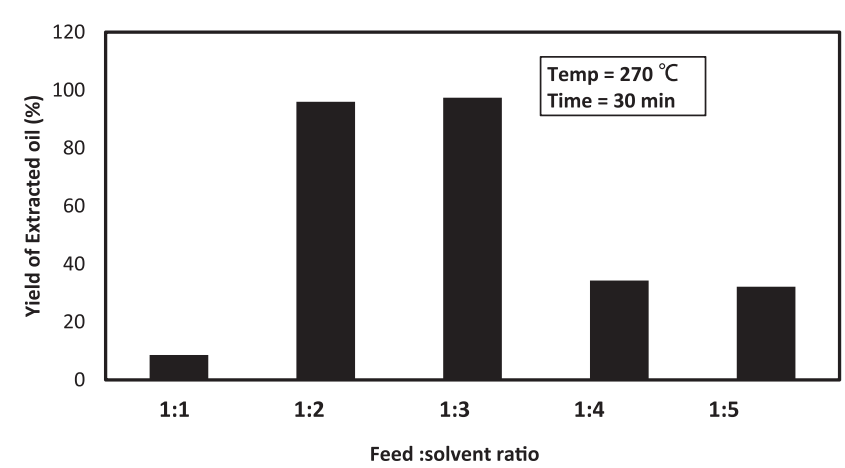

Fig. 3 The effect of the feed to solvent ratio on the yield of extracted oil.

Table 1 Physical properties of extracted castor oil.

\begin{tabular}{lc}
\hline \multicolumn{1}{c}{ Property } & Extracted Castor oil \\
\hline Acid Value, $(\mathrm{mg} \mathrm{KOH} / \mathrm{g}$ oil $)$ & 1.094 \\
Specific gravity $25^{\circ} \mathrm{C}, \mathrm{g} / \mathrm{cm}^{3}$ & 0.947 \\
Viscosity at $25^{\circ} \mathrm{C}(\mathrm{cp})$ & 7.487 \\
$\mathrm{pH}$ Value & 6.10 \\
Calorific Value $(\mathrm{MJ} / \mathrm{Kg})$ & 41.5 \\
\hline
\end{tabular}

matograms and the composition of the fatty acids in castor oil samples extracted by subcritical water technology (SWT) and conventional solvent extraction using methanol. The FAME profiles of both samples were generally similar as all major peaks appeared in both samples (Fig. 4). The most predominant peaks are of the ricinoleic fatty acid methyl esters represented by two peaks for the $(R)$ - and (S) - enantiomers. They were present as $83.6 \%$ and $75.7 \%$ in oil extracted by SWT and conventional solvent extraction, respectively. Methyl esters of oleic (5.5\% and 7.4\%) and linoleic $(2.3 \%$ and $2.4 \%)$ acids were also present in castor oil extracted by SWT and conventional solvent extraction, respectively.

These results are in agreement with previous results obtained for the fatty acid content of castor oil using pneumatic press followed by extraction with hexane ${ }^{23)}$ showing ricinoleic acid as the main fatty acid (86\%) followed by linoleic acid $(5.5 \%)$ and oleic acid $(3.6 \%)$. The results are as

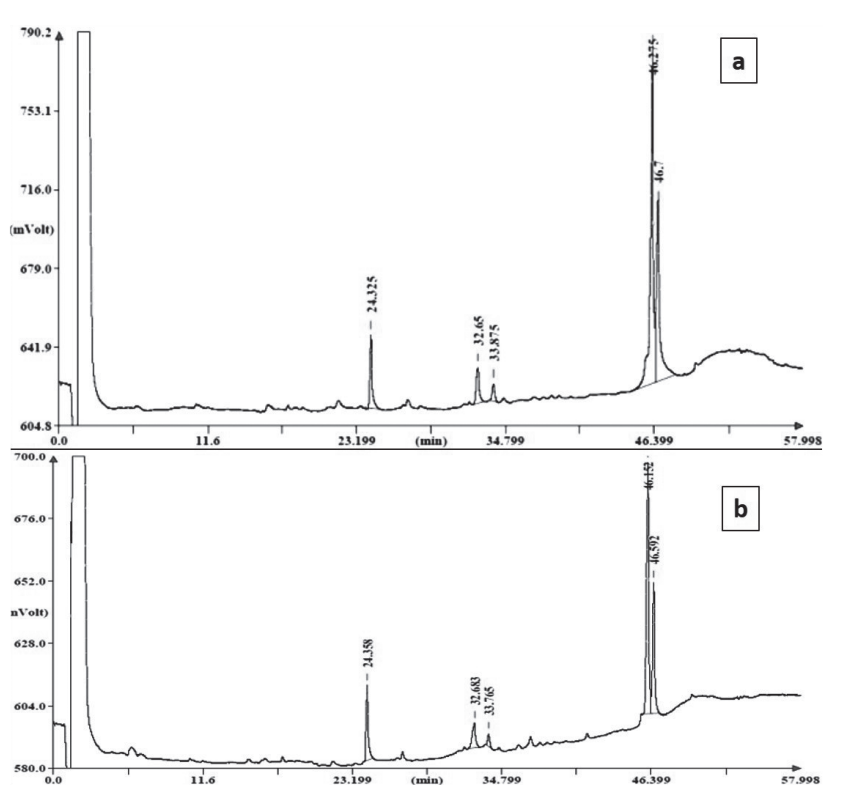

Fig. 4 GLC chromatogram of FAME of castor oil; (a) oil extracted by SWT, (b) oil extracted by conventional solvent extraction.

well comparable with the fatty acid content of cold pressed castor seeds ${ }^{15)}$ where ricinoleic acid comprised over $89 \%$ of the fatty acid content of the oil followed by linoleic $(4.2 \%)$, oleic $(3.0 \%)$, stearic $(1 \%)$, palmitic $(1 \%)$, dihydroxystearic $\operatorname{acid}(0.7 \%)$, linolenic acid $(0.3 \%)$, and eicosanoic acid $(0.3 \%)$. More detailed comparison of the difference in extraction behavior of various kinds of oil from different biomasses using subcritical water will be addressed in future work.

\subsection{Kinetics of the oil extraction process for castor oil}

The kinetic study of the oil extraction from castor seed under subcritical water conditions was based on consecutive steps. In these steps, the oil was first extracted from inside the powder by diffusion following a first order-like mechanism. Then the extracted oil, due to extending the extraction time under high temperature and pressure, was subjected to a decomposition reaction following a first order mechanism. Figure 2 shows the time course of the

Table 2 Percentage of the major FAME in Castor oil samples.

\begin{tabular}{|c|c|c|c|}
\hline \multirow[b]{2}{*}{$\begin{array}{l}\text { Retention } \\
\text { time (min) }\end{array}$} & \multirow[b]{2}{*}{ Fatty acids } & \multicolumn{2}{|c|}{ Percentage $\%$} \\
\hline & & $\begin{array}{c}\text { Conventional } \\
\text { solvent extraction }\end{array}$ & $\begin{array}{c}\text { Subcritical water } \\
\text { extraction }\end{array}$ \\
\hline 24.4 & Not identified & 14.4 & 8.6 \\
\hline 32.6 & Oleic acid (C18:1) & 7.4 & 5.5 \\
\hline 33.8 & Linoleic acid (C18:2) $\omega-6$ & 2.4 & 2.3 \\
\hline 46.3 & (Ricinoleic acid) & 50.8 & 51 \\
\hline 46.7 & (Ricinoleic acid) & 24.9 & 32.6 \\
\hline
\end{tabular}


Table 3 Rate constants of oil extraction and decomposition at different extraction temperatures.

\begin{tabular}{ccc}
\hline Temperature $\left({ }^{\circ} \mathrm{C}\right)$ & $\begin{array}{c}\text { Oil Extraction } \\
\text { Rate, } \mathrm{k}_{1}\left(\mathrm{~min}^{-1}\right)\end{array}$ & $\begin{array}{c}\text { Oil Decomposition } \\
\text { Rate, } \mathrm{k}_{2}\left(\mathrm{~min}^{-1}\right)\end{array}$ \\
\hline 240 & 0.0019 & 0.057 \\
250 & 0.024 & 0.059 \\
260 & 0.098 & 0.014 \\
270 & 0.1 & 0.019 \\
280 & 0.117 & 0.17 \\
\hline
\end{tabular}

concentration of the extracted oil at different temperatures in the tested range $(240-280)^{\circ} \mathrm{C}$.

The experimental data were well correlated with the irreversible consecutive unimolecular-type first order mechanism using equation(4). The values of both oil extraction rate constant and decomposition rate constant were calculated through non-liner fitting using DataFit software (version 9.1; Oakdale Engineering, Oakdale, PA, http:// www.oakdaleengr.com/datafit.htm). Table 3 shows the obtained values of the rate constants. The extraction rate constants were $0.0019,0.024,0.098,0.1$ and $0.117 \mathrm{~min}^{-1}$, while the decomposition rate constants were $0.057,0.059$, $0.014,0.019$ and $0.17 \mathrm{~min}^{-1}$ at extraction temperatures of $240,250,260,270$ and $280^{\circ} \mathrm{C}$, respectively. The results showed that by increasing the extraction temperature, the extraction rate increases. However, the decomposition rate increased up to a certain value then became almost constant by increasing the extraction temperatures.

\subsection{Thermodynamic parameters}

The thermodynamic properties of the oil extraction process was investigated and Fig. 5 shows Arrhenius plot for the process. This plot represents the relation between the inverse of the absolute extraction temperature on the $\mathrm{x}$-axis and the extraction rate constant on the y-axis. The values of the slope and the intercept were 8780.9 and 13.76 , respectively. The activation energy, Ea, and the fre-

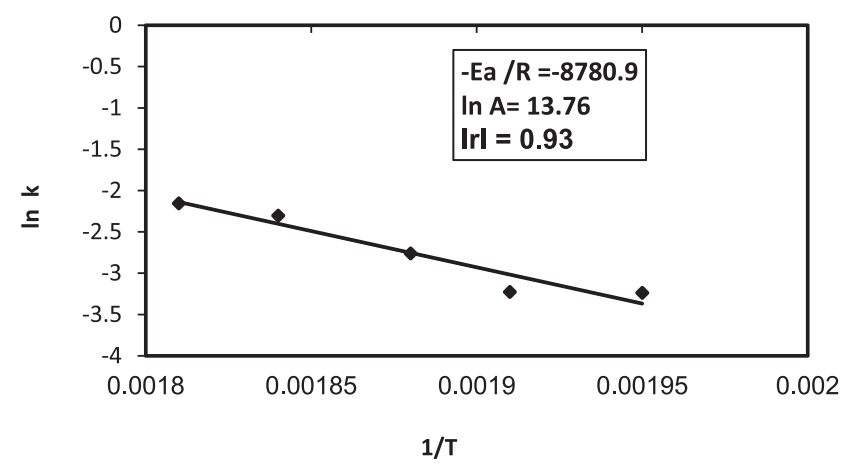

Fig. 5 Arrhenius plot of oil extraction in the range of 240 $-280^{\circ} \mathrm{C}$. quency factor, A, were calculated from these values using equation(5). Accordingly, the values of Ea and A were 73 $\mathrm{kJ} \mathrm{mol}^{-1}$ and $946002 \mathrm{~min}^{-1}$, respectively for castor seed oil. The value for the activation energy indicates a semi diffusion control process which mean both diffusion and reaction are controlling the process with predominate diffusion control over the process.

\section{Conclusion}

In this work, subcritical water extraction technology (SWT) was used to extract castor seed oil. The optimum conditions needed to obtain a maximum yield of castor oil was determined. The kinetics as well as the thermodynamics of the SWT extraction process of castor oil was investigated where the obtained results revealed that an increase in both temperature and time of extraction improved the yield of extraction up to certain limits. The physicochemical properties of the oil was determined as well as the fatty acid content. Finally, it can be concluded that the subcritical water extraction is a promising technique as it can definitely extract oils with qualities comparable to those extracted by traditional solvent extraction with the added advantage of being a quicker and a very clean method which avoids both, the use of large amounts of organic solvent and generation of toxic residues.

\section{Acknowledgment}

The authors thank the Science and Technology Development Fund (STDF), Academy for Scientific Research \& Technology, Egypt for financial support (STDF-NRG, project ID: 5767).

\section{Reference}

1) Abdelmoez, W.; Yoshida, H. Synthesis of a novel protein-based plastic using sub-critical water technology. AIChE J. 52, 2607-2617(2006).

2) Abdelmoez, W.; Ashour, E.; Naguib, S. M. A Review on Green Trend for Oil Extraction Using Subcritical Water Technology and Biodiesel Production. J. Oleo Sci. 64, 467-478(2015).

3) Yoshida, H.; Terashima, M.; Takahashi, Y. Production of Organic Acids and Amino Acids from Fish Meat by Sub-Critical Water Hydrolysis. Biotechnol. Prog. 15, 1090-1094 (1999).

4) Eikani, M. H.; Golmohammad, F.; Rowshanzamir, S. Subcritical water extraction of essential oils from coriander seeds (Coriandrum sativum L.). J. Food Eng. 80, 735-740 (2007). 
5) Abdelmoez, W.; Abdelfatah, R.; Tayeb, A.; Yoshida, H. Extraction of cottonseed oil using subcritical water technology. AIChE J. 57, 2353-2359 (2011).

6) Abdelmoez, W.; Abdelhamid, M.; Yoshida, H. Extraction of jojoba oil using subcritical water technology. Recent Pat. Chem. Eng. 5, 63-70 (2012).

7) Ravber, M.; Knez, Ž.; Škerget, M. Simultaneous extraction of oil-and water-soluble phase from sunflower seeds with subcritical water. Food Chem. 166, 316$323(2015)$.

8) Abdelmoez, W.; Nage, S. M.; Bastawess, A.; Ihab, A.; Yoshida, H. Subcritical water technology for wheat straw hydrolysis to produce value added products. $J$. Cleaner Prod. 70, 68-77 (2014).

9) Wheatley, G. W.; Davison, K. WO 2010034971 A2 (2009).

10) Liang, X.; Fan, Q. Application of sub-critical water extraction in pharmaceutical industry. J. Mater. Sci. Chem. Eng. 1, 1-6 (2013).

11) Kubatova, A.; Miller, D. J.; Hawthorne, S. B. Comparison of subcritical water and organic solvents for extracting kava lactones from kava root. J. Chromatogr. A 923, 187-194(2001).

12) Aliakbarian, B.; Fathi, A.; Perego, P.; Dehghani, F. Extraction of antioxidants from winery wastes using subcritical water. J. Supercrit. Fluids 65, 18-24(2012).

13) Zeković, Z.; Vidović, S.; Vladić, J.; Radosavljević, R.; Cvejin, A.; Elgndi, M. A.; Pavlić, B. Optimization of subcritical water extraction of antioxidants from Coriandrum sativum seeds by response surface methodology. J. Supercrit. Fluids 95, 560-566 (2014).

14）Baek, J.-Y.; Lee, J.-M.; Lee, S.-C. Extraction of nutraceutical compounds from licorice roots with subcritical water. Sep. Purif. Technol. 63, 661-664(2008).

15) Ogunniyi, D. Castor oil: A vital industrial raw material.
Bioresour. Technol. 97, 1086-1091(2006).

16) Madankar, C. S.; Pradhan, S.; Naik, S. Parametric study of reactive extraction of castor seed (Ricinus communis L.) for methyl ester production and its potential use as bio lubricant. Ind. Crops Prod. 43, 283290 (2013).

17) Sánchez, N.; Encinar, J. M.; Martínez, G.; González, J. F. Biodiesel Production from Castor Oil under Subcritical Methanol Conditions. Int. J. Environ. Sci. Dev. 6, 61-66 (2015).

18) Silitonga, A.; Masjuki, H.; Mahlia, T.; Ong, H.; Chong, W.; Boosroh, M. Overview properties of biodiesel diesel blends from edible and non-edible feedstock. Renewable Sustainable Energy Rev. 22, 346-360 (2013).

19) Mofijur, M.; Atabani, A.; Masjuki, H.; Kalam, M.; Masum, B. A study on the effects of promising edible and non-edible biodiesel feedstocks on engine performance and emissions production: a comparative evaluation. Renewable Sustainable Energy Rev. 23, 391404(2013).

20) Dasari, S. R.; Goud, V. V. Comparative Extraction of Castor seed Oil Using Polar and Non polar Solvents. Int. J. Curr. Eng. Technol. 1, 121-123(2013).

21) Vogel, A. I. A textbok of practical organic chemistry, Edn. 3. (Longmans and Green Co. Ltd., London; 1975).

22) Akubugwo, I.; Chinyere, G.; Ugbogu, A. Comparative studies on oils from some common plant seeds in $\mathrm{Ni}$ geria. Pak. J. Nut. 7, 570-573(2008).

23) Martín, C.; Moure, A.; Martín, G.; Carrillo, E.; Domínguez, H.; Parajó, J. C. Fractional characterisation of jatropha, neem, moringa, trisperma, castor and candlenut seeds as potential feedstocks for biodiesel production in Cuba. Biomass Bioenerg. 34, 533-538 (2010). 